\title{
Is Personalized Service No Longer Important? Guests of Smart Hotels May Have Other Preferences
}

\author{
Wan Peng, Mu Zhang \\ Shenzhen Tourism College, Jinan University, Overseas Chinese Town, Shenzhen, China \\ Email: pengwan@sz4211.net, zhangmu@jnu.edu.cn
}

How to cite this paper: Peng, W., \& Zhang, M. (2020). Is Personalized Service No Longer Important? Guests of Smart Hotels May Have Other Preferences. Journal of Service Science and Management, 13, 535-557.

https://doi.org/10.4236/jssm.2020.133035

Received: May 8, 2020

Accepted: June 13, 2020

Published: June 16, 2020

Copyright $\odot 2020$ by author(s) and Scientific Research Publishing Inc. This work is licensed under the Creative Commons Attribution International License (CC BY 4.0).

http://creativecommons.org/licenses/by/4.0/

\section{(c) (i) Open Access}

\begin{abstract}
Given the promising growth of smart tourism and smart cities, increasing attention has been paid to smart hotels. Through field survey and corpus analysis, some service issues were found (e.g., complicated processes), and the theoretical, as well as the practical significance of improving service quality in smart hotels, were explored. In this paper, we adopted the SERVQUAL model in smart hotels to evaluate the gap between perceived services (PS) and expected services (ES) of guests across five dimensions (i.e., tangibles, reliability, responsiveness, assurance, and empathy). Following the importance as well as service quality (SQ) ranking of 211 participants, our survey results demonstrated the crucial role of tangibles while the significance of empathy was marked down. The highest and lowest SQ scores were tangibles and assurance. These outcomes highlighted the existing distinctiveness of smart hotels, re-examined the fundamentals of personalized services, and itemized the implications associated with the service optimization of smart hotels.
\end{abstract}

\section{Keywords}

Smart Hotel, Hotel Industry, Service Quality, SERVQUAL

\section{Introduction}

Nowadays, as smart tourism gradually receives great attention and becomes applicable in various tourist cities, the hotel industry, an essential part of tourism's pillar industries, began to incorporate smart hotels in its business model (Jeremen, Jędrasiak, \& Rapacz, 2016). Simultaneously, economic globalization has led to the excessive and rapid expansion of overheated investments in the hotel industry. The traditional quality, quantity, and price competition, such as hotel 
capacity and interior designs or decorations, are no longer the central issues. Fierce internal competition in the hotel industry, accompanied by increasing external expectations, have prompted insiders to seek more effective ways to boost sales, reduce costs, and optimize services. As expected, smart hotels dominated the race to a sustainable and competitive transformation through their renowned large-scale applications of automation technology (Zhong \& Gao, 2017). Furthermore, this new hospitality solution utilizes emerging information technologies, such as the Internet of Things, cloud computing, and mobile Internet. It adopts smart terminals, artificial intelligence, and other devices as carriers to create a complete intelligent system. The ultimate goals of smart hotels are to achieve exceptional customer service that focuses on empathy and promote efficient management (Zhong \& Gao, 2017; Wu \& Cheng, 2018; Nizic, Karanovic, \& Ivanovic, 2008).

In 2015, the Henn-na Hotel, the world's first smart hotel operated by fully automated devices and robots, opened in Nagasaki, Japan. In 2018, international hotel groups such as Marriott, IHG (i.e., InterContinental Hotels Group), Hilton, and Shangri-La began to rely on the overflow of formidable capital and technological support toward the smart hotel industry.

Since the COVID-19 outbreak, smart hotels became the center of public discussion. Given the risks of transmission and infection, the advantages of the contactless service became highly relevant and advantageous, as it primarily reduces direct physical contact between individuals.

In this crucial period, smart hotels equipped with sufficient terminals and robots can be on duty 24 hours daily for the timely accommodation of customer needs. In the past, the majority of criticisms revolved around the "lack of humanized customer experience" in smart hotels, which has today become the most suitable approach in maintaining social distancing and enhancing security. While this period undoubtedly places smart hotels under such severe conditions, it also brings out their potentials and significance, which could stimulate a new round of advancement opportunities for this innovative approach.

After nearly a decade of construction, smart hotels no longer remain a groundless concept but have become another essential topic after "smart city" and "smart tourism" (Wu, 2019b). The increase in practical applications of smart hotels led to the gradual expansion and improvements of relevant literature.

Overall, prior studies on smart hotels often focused on the core technologies and intelligent management systems, such as the vital roles of information technology (Chathoth, 2007; Yao \& Han, 2013), tentative automation system architecture (Venkatesh et al., 2013; Stepan et al., 2018), and application research on the integration of management systems like property management system (PMS) and human resources management system (HRMS) (Kapnas et al., 2013; Jeremen, Jędrasiak, \& Rapacz, 2016; Wang, Bao, \& Yang, 2017). As the third wave of informatization transitions the world into the era of big data, cloud computing, and the Internet of Things, some scholars began to construct the $5 \mathrm{G}$ 
applications in future smart hotels. More specifically, they analyzed its feasibility ( $\mathrm{Wu}, 2019 \mathrm{c}$ ), and proposed that smart hotels should consider connecting the basic subsystems into one whole system (Zeng \& Lu, 2017). Moreover, sustainable development scholars also recommended to utilize renewable energy and recyclable equipment to maintain daily operations (Andreea \& Simona, 2017).

While technological research is progressing by leaps and bounds, an increasing number of scholars are turning their attention toward factors that enhance the overall hotel service experience and management efficiency of smart hotels.

On the one hand, some empirical studies have verified the effectiveness of digital media integration in providing customized immersive services for future hotels (Tuominen \& Ascenção, 2016), and the positive impact of big data precision marketing on elevating the guest experience (Zhong \& Gao, 2017). On the other hand, some scholars have confirmed that the combination of informatization, interaction, and personalization substantially impacts customer experience (Jeong \& Shin, 2019). Furthermore, there is a positive correlation between smart hotel technology attachment, experiential relationship quality, and experiential sharing intentions, as well as a negative correlation between experiential risk and sharing intentions (Wu \& Cheng, 2018).

To improve the efficiency of management mechanisms, scholars have examined and demonstrated the positive effects of service, marketing, and management intelligence on hotel performance (Xiong \& Wu, 2018). They further predict that the future development trend of smart hotels will significantly reduce the number of employees while increasing both age diversity and their functional responsibilities (Solnet et al., 2016).

As these studies extensively substantiate the core technology research and management strategies, there is notable scarcity in studies with empirical evidence on the significance of smart hotels and the investigation of their distinctive services. This state implies that recent research on smart hotel service remains stagnant and insufficient.

However, the corpus analysis of smart hotel reviews on the online travel agency (OTA) platform and field survey found an unanticipated phenomenon. That is, despite smart hotels transforming their service providers into intelligent devices, the process and modes remain highly similar to the traditional star hotels. To make matters worse, the negative reviews on the online platforms also point directly to service issues. Overall, this suggests that the development of smart hotel services does not have an optimistic outlook.

For example, some operators consider that decoration and equipment upgrades, while immensely focusing on technological applications, are the critical points of a smart hotel. They attempt to satisfy customer needs by merely replicating various information, equipment, and systems. However, oversight of technical limitations and conditions of these technologies could impede managers in hiring the right experts, ultimately leading to a substandard customer service experience ( $\mathrm{Wu}, 2019 \mathrm{a})$.

Furthermore, the way that managers use artificial intelligence to decrease la- 
bor costs and improve service consistency made the operators less vigilant. The over-reliance of employees on technological equipment has affected their critical thinking and level of involvement in developing systems and processes. Consequently, this has made them perfunctory at work. Complex systems and procedures progressively emerge as these hotels directly imitate the services and experiences offered by traditional luxury hotels (Zhong \& Gao, 2017).

Therefore, assessing the current status of smart hotel services and making targeted improvements have remained inevitable and problematic amid the benign development of smart hotels.

In 1991, Parasuraman, Zeithaml, and Berry (PZB) proposed and applied the SERVQUAL model to an empirical measurement of a four-star hotel in Canada (Parasuraman, Zeithaml, \& Berry, 1988; Saleh \& Ryan, 1991). Subsequently, its practical application in the hotel industry became more prevalent. In the hotel industry context, scholars conducted an extensive and comprehensive discussion on service quality around three aspects, namely element composition, internal structure, and model empirical research. Some research papers on service quality classify the hotel guests according to their cultural backgrounds and whether their arrivals occur in the low or high season (Armstrong et al., 1997; Tribe \& Snaith, 1998). There are also studies combining the different evaluation models with the SERVQUAL model to examine its practicality and reliability (Stefano et al., 2015; Beheshtinia \& Azad, 2019).

The development of the SERVQUAL model came with some reservations about the dimensions and reliability of the scale (Carman, 1990; Babakus \& Boller, 1992). However, with continuous improvements, the reliability and validity of these five dimensions and items greatly improved. Numerous scholars and enterprises recognized its applicability (Chen \& Wang, 2005).

Despite the substantial changes in the technical equipment and service providers of smart hotels, their service processes and approach remain significantly similar to traditional star hotels. Thus, the SERVQUAL model, renowned in the traditional hotel industry for representing consumer perceptions and expectations for particular service, is suitable in evaluating service quality in smart hotels.

In this article, we use a reliable SERVQUAL model to measure the service status of smart hotels. Combining literature research, field survey, corpus analysis, and questionnaires, we quantitatively evaluate the expectations and perceptions of consumers based on five dimensions of smart hotel service quality: tangibles, reliability, responsiveness, assurance, and empathy.

In this article, we aim to use the reliable SERVQUAL model to measure the service status of smart hotels. Firstly, we combined literature research, field survey, and corpus analysis during the preliminary research to make a general assessment of the smart hotels' current status. Subsequently, expectations and perceived scores on the five dimensions of smart hotel service quality (tangibles, reliability, responsiveness, assurance, and empathy) were evaluated using questionnaires and Delphi methods. The result confirms the distinctiveness of smart 
hotel services, enhances the detailed empirical research outcomes, and recommends a new direction for the future development of smart hotels.

\section{Preliminary Research}

To understand the differences between smart hotels and traditional hotels in terms of facility, service, and management more objectively, we conducted the pre-investigation, field survey, and corpus analysis of the status of smart hotels, all before the formal questionnaire. The results highlighted the evident particularity of smart hotels and served as the foundation for the formal questionnaire items and research hypothesis.

\subsection{Field Survey}

The field survey selected two unmanned smart hotels in Shenzhen, Guangdong Province, China, which aimed to restore the actual appearance of smart hotels through photos, videos, and interviews. Both of these hotels are Leyeju smart hotels that already have multiple chain stores in China. They are located in a prosperous business district in Shenzhen and opened in 2018 and 2019, respectively. According to Leyeju's official website and APP, the notable "unmanned" and "smart" features are reflected in their mobile phone booking and check-out, facial recognition check-in, intelligent robot, smart inductive lock, and diverse in-room IoT and sensors.

The investigation shows that these two smart hotels are in line with the official description except that they are not equipped with intelligent robots. Starting from booking a room, checking-in to checking-out, the whole process was completed through the electronic system. Both the hotel lobby and rooms have passwords, and as soon as the customer has successfully booked online, the hotel lobby passwords will be sent through a text message. After a successful facial recognition and identity authentication at the self-service terminal system in the lobby, the management system will automatically assign a room number and set of passwords, which are sent through a message again. Without making further actions after entering the room, the lights, curtains, air conditioners, and TV will turn on automatically, eliminating the step of using a traditional room card.

Besides, although there is no front desk or employees, both Leyeju hotels have a single-operator desk inside the lobby. Strangely, only one hotel has an employee on duty, and the other has an empty office. Our respondent stated that the hotel would arrange one person to take over all external affairs daily, including assisting guests who are unable to use the self-service terminal, handling engineering issues, and addressing other individual concerns. Additionally, the respondent said that since there are minimal requests for assistance, reports for malfunctions, and group check-in, most of the guests choose to complete their check-in and check-out on their own. As a result, sometimes, one employee will take over both branches.

When asked about the differences between smart hotels and traditional hotels, 
the response was that employees in smart hotels have fewer face-to-face communications with guests. In contrast, traditional hotels highly prioritize their customer service. Therefore, employees in smart hotels have more freedom and flexibility to make independent decisions, since they are no longer subject to the multi-level jurisdiction. Moreover, the guests focus on the experience of intelligent systems throughout the hotel, and rarely have disputes with the employee.

Table 1 summarizes the field survey and interview and compares the Leyeju smart hotels and traditional hotels. Figures B1-B3 show the photos of the field survey.

\subsection{Corpus Analysis of Comments on OTA}

To obtain the comments of smart hotels' guests, we utilize the data crawler software to collect relevant comments in China's leading hotel reservation platforms, such as Ctrip and eLong. Given a large number of eligible hotels, we selected 20 long-established smart hotels or apartments, which have sufficient comments to complete the corpus analysis. We collected 5962 comments, and Table 2 shows the distribution of the positive comments (4.0 - 5.0, 4457 comments), medium (3.0 - 4.0, 1213 comments), and negative comments (3.0 or less, 292 comments). We deleted the adverbs, prepositions, numbers, pronouns, conjunctions, and their respective positions in the comments. Figure 1 illustrates the word cloud diagram of our corpus analysis.

The top five most useful and frequent information appearing in the positive comments are "cost-effective, intelligent, robot, convenient, affordable". The top five medium and negative comments are "affordable, no service, no breakfast, no extra bed, no parking" and "no employees, hard to contact the customer service, power off, no elevator, formaldehyde." The majority of positive comments highlight

Table 1. Comparison between smart hotels and traditional hotels.

\begin{tabular}{|c|c|c|}
\hline Comparison & Smart Hotels & Traditional Hotels \\
\hline Booking Method & \multicolumn{2}{|c|}{ OTA, official website and WeChat account } \\
\hline Total Cost & $220-350$ yuan & $300-500$ yuan \\
\hline Additional Service & No & Meeting rooms, etc. \\
\hline Room Devices & Intelligent induction system & Traditional equipment \\
\hline Service & Terminals and robots & Hotel employees \\
\hline Management & Flat management & Pyramid management \\
\hline Negative Comments & Most caused by intelligent devices & Most caused by service attitudes \\
\hline 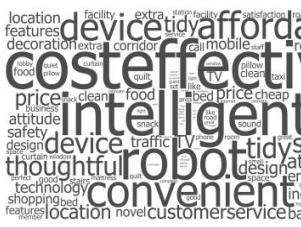 & 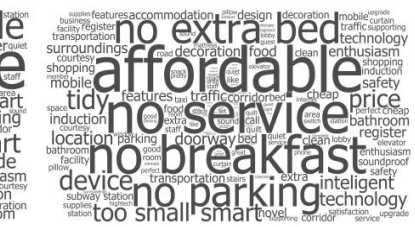 & 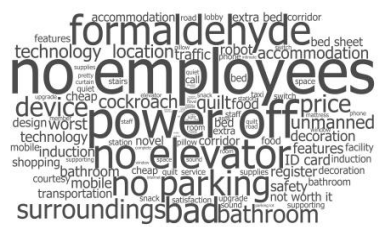 \\
\hline
\end{tabular}

Figure 1. Word clouds of the comments. 
Table 2. Data distribution of corpus analysis.

\begin{tabular}{|c|c|c|}
\hline Subjects & Location & Amount \\
\hline Leyeju Smart Hotel & Shenzhen, Guangdong (Bagualing) & 604 \\
\hline Leyeju Smart Hotel & Shenzhen, Guangdong (Dongmen) & 582 \\
\hline Leyeju Smart Hotel & Shenzhen, Guangdong (Yantian) & 383 \\
\hline Leyeju Smart Hotel & Guangzhou, Guangdong (Jiayu Wanggang) & 118 \\
\hline Leyeju Smart Hotel & Changzhou, Jiangsu (Bell Tower) & 114 \\
\hline Leyeju Smart Hotel & Chengdu, Sichuan (Wuhouyu) & 304 \\
\hline Leyeju Smart Hotel & Chengdu, Sichuan (Global Center) & 1276 \\
\hline Flyzoo Hotel & Hangzhou, Zhejiang & 115 \\
\hline CitiWow Hotel & Hebei Baoding (Baoding Bus Station) & 229 \\
\hline Candy Xbed Hotel & Changsha, Hunan & 1381 \\
\hline Xbed Apartment & Xi'an, Shaanxi (Xi'an Stadium) & 146 \\
\hline Xbed Apartment & Shenzhen, Guangdong (Jiayurun) & 72 \\
\hline Muxi Unmanned Hotel & Chengdu, Sichuan & 114 \\
\hline Aitu Unmanned Apartment & Chengdu, Sichuan (No. 4) & 91 \\
\hline Aitu Unmanned Apartment & Chengdu, Sichuan (No. 6) & 113 \\
\hline Wanjin Fengshe Unmanned Hotel & Wenzhou, Zhejiang Province & 131 \\
\hline City Home Smart Apartment & Shanxi Shuozhou (Jinshan) & 37 \\
\hline City Home Smart Apartment & Shanxi Shuozhou (Boyuan) & 46 \\
\hline City Home Smart Apartment & Shanxi Shuozhou (Vientiane City) & 74 \\
\hline City Home Smart Apartment & Shanxi Shuozhou (Henderson) & 32 \\
\hline Leyeju Smart Hotel & Shenzhen, Guangdong (Bagualing) & 604 \\
\hline Leyeju Smart Hotel & Shenzhen, Guangdong (Dongmen) & 582 \\
\hline Leyeju Smart Hotel & Shenzhen, Guangdong (Yantian) & 383 \\
\hline Leyeju Smart Hotel & Guangzhou, Guangdong (Jiayu Wanggang) & 118 \\
\hline Leyeju Smart Hotel & Changzhou, Jiangsu (Bell Tower) & 114 \\
\hline Leyeju Smart Hotel & Chengdu, Sichuan (Wuhouyu) & 304 \\
\hline Leyeju Smart Hotel & Chengdu, Sichuan (Global Center) & 1276 \\
\hline Flyzoo Hotel & Hangzhou, Zhejiang & 115 \\
\hline CitiWow Hotel & Hebei Baoding (Baoding Bus Station) & 229 \\
\hline Candy Xbed Hotel & Changsha, Hunan & 1381 \\
\hline Xbed Apartment & Xi'an, Shaanxi (Xi'an Stadium) & 146 \\
\hline Xbed Apartment & Shenzhen, Guangdong (Jiayurun) & 72 \\
\hline Muxi Unmanned Hotel & Chengdu, Sichuan & 114 \\
\hline Aitu Unmanned Apartment & Chengdu, Sichuan (No. 4) & 91 \\
\hline Aitu Unmanned Apartment & Chengdu, Sichuan (No. 6) & 113 \\
\hline Wanjin Fengshe Unmanned Hotel & Wenzhou, Zhejiang Province & 131 \\
\hline City Home Smart Apartment & Shanxi Shuozhou (Jinshan) & 37 \\
\hline City Home Smart Apartment & Shanxi Shuozhou (Boyuan) & 46 \\
\hline City Home Smart Apartment & Shanxi Shuozhou (Vientiane City) & 74 \\
\hline City Home Smart Apartment & Shanxi Shuozhou (Henderson) & 32 \\
\hline
\end{tabular}


the convenience of intelligent technology. At the same time, the lack of services such as extra beds, breakfast, parking lot, elevator, and 24-hour front desk duty in traditional star hotels are the main drivers of negative comments. Besides, since most smart hotels only opened for less than two years, excessive formaldehyde also remains a significant cause of complaints.

Furthermore, since the majority of smart hotels are positioned mid-range and have insufficient investments in catering and parking services, they also contribute to the complaints. Some smart hotels do not have elevators to minimize costs from purchasing and maintaining additional equipment. The smart technology equipment has made corresponding substitutions for booking, registration, check-in, and delivery services. However, there are remaining problems related to a power outage, long waiting time when contacting customer service, and unresolved service requests such as for an extra bed.

The corpus analysis findings underline that the guests still have high expectations for services, and the service quality in most smart hotels has not yet fulfilled their expectations.

\subsection{Hypothesis}

As is seen in the field survey, smart hotels are reasonably different from traditional star hotels in terms of management and service mode, making it necessary to establish unique operating and service strategies. Additionally, the corpus analysis results show that while most of the guests praise the exceptional facilities, they consider the slow response speed and lack of service as worse than expected. It turns out that the tangibles and reliability of smart hotels perform better than their expectations, but the responsiveness, assurance, and empathy need to be significantly improved.

Based on the preliminary research, we propose the following hypotheses.

- $\mathrm{H}$ : The perceived service of the entire smart hotel is worse than the expected service.

- Ha: The perceived service of tangibles in a smart hotel is better than the expected service.

- $\mathrm{Hb}$ : The perceived service of reliability in a smart hotel is better than the expected service.

- Hc: The perceived service of responsiveness in a smart hotel is worse than the expected service.

- Hd: The perceived service of assurance in a smart hotel is worse than the expected service.

- He: The perceived service of empathy in a smart hotel is worse than the expected service.

\section{Methodology}

The SERVQUAL scale is based on the gap between the guests' expectations and perceptions of the service quality. Generally, the scale is composed of 22 items, 
which are divided into five dimensions: tangibles, reliability, responsiveness, assurance, and empathy. The SERVQUAL model and theory explain the five dimensions as:

- Tangibles: physical facilities, equipment, and company appearance;

- Reliability: the ability of companies to perform the promised service accurately and consistently;

- Responsiveness: the willingness of companies to help customers and respond promptly;

- Assurance: the ability and courtesy of employees to inspire the trust of customers;

- Empathy: caring and individualized services.

As shown in Figure 2, the evaluation principle of the SERVQUAL model is using the guests' perceived services (PS) score of the five dimensions minus the corresponding expected services (ES) score, and the resulting difference is the final score for perceived service quality (SQ).

This study combines the real situation of smart hotels, and previous questionnaires obtain a Likert scale composed of 20 items as the pre-questionnaire (Parasuraman, Zeithaml, \& Berry, 1988; Dang \& Zhou, 2002; Chen \& Wang, 2005; Kong, You, \& Hou, 2011). Table A1 itemizes the entire questionnaire.

\subsection{Questionnaire and Pilot Study}

Seventy-eight guests who have experience staying in smart hotels participated in this pretest. Among them, there are 30 males (38.5\%) and 48 females (61.5\%), respondents are between 19 - 30 years old, and personal monthly incomes range from 10,000 to 20,000 Yuan, accounting for $69.2 \%$ and $41.0 \%$ respectively. The sample distribution is in line with the actual situations of smart hotel guests.

Using Cronbach's alpha to analyze the reliability and applying the principal exploratory factor analysis to examine the validity based on SPSS24.0, we generate the results shown in Table 3 and Table 4.

As seen in Table 3, except for the reliability of tangibles' expectations at 0.611 , the reliability of other dimensions in either expectations or perceptions is higher than 0.7, indicating that the questionnaire has good reliability (Nunnally, 1978). Moreover, the data in Table 4 shows that the overall Kaiser-Meyer-Olkin (KMO) of the questionnaire is 0.717 , and the Bartlett spherical test is also significant at the 0.01 level, demonstrating that the questionnaire has excellent validity

\section{SERVQUAL Dimensions}

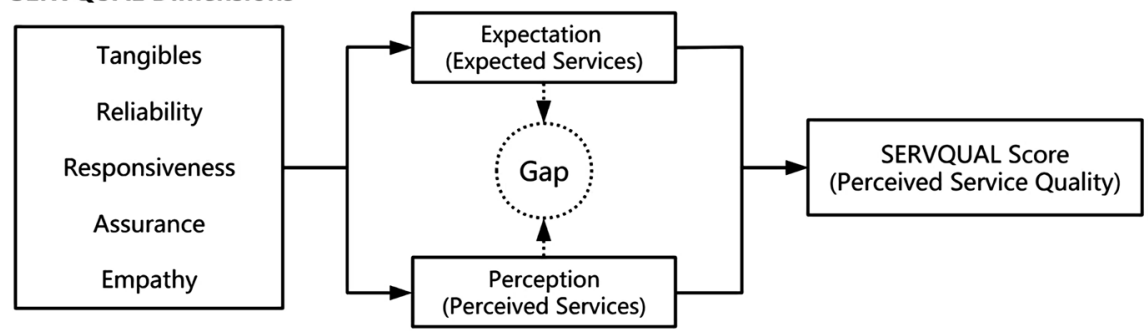

Figure 2. SERVQUAL model. 
Table 3. Reliability of the pilot study.

\begin{tabular}{cccc}
\hline Dimension & Expectation & Perception & Service Quality \\
\hline tangibles/A & 0.611 & 0.793 & 0.746 \\
Reliability/B & 0.808 & 0.870 & 0.807 \\
Responsiveness/C & 0.792 & 0.863 & 0.824 \\
Assurance/D & 0.864 & 0.838 & 0.819 \\
Empathy/E & 0.817 & 0.830 & 0.828 \\
Overall & 0.906 & 0.933 & 0.936 \\
\hline
\end{tabular}

Table 4. Validity of the pilot study.

\begin{tabular}{ccccc}
\hline Variable & KMO & Bartlett & df & Sig. \\
\hline Expectation items & 0.795 & 873.742 & 190 & $0.000^{\mathrm{a}}$ \\
Perception items & 0.819 & 1066.097 & 190 & $0.000^{\mathrm{a}}$ \\
Overall & 0.717 & 2410.886 & 780 & $0.000^{\mathrm{a}}$ \\
\hline
\end{tabular}

${ }^{a}$ Significant at the 0.01 level (2-tailed).

and is suitable for factor analysis (Kaiser, 1960). Then, the study uses the principal component analysis to conduct exploratory factor analysis on all five dimensions. Table 5 shows the load table of each factor in the corresponding dimension. The cumulative variance contribution rates of these five dimensions are $56.462 \%, 69.105 \%, 67.804 \%, 70.011 \%$, and $65.674 \%$, respectively. These results further validate the questionnaire, indicating that the pre-questionnaire can be used as the formal questionnaire directly.

\subsection{Weights by the Delphic Approach}

As a basis for subsequent SQ calculations, this study adopts the Delphi method to build an indicator system for evaluating the service quality of smart hotels, including the weight ratio of 5 first-level indicators and 20 second-level indicators (Khorramshahgol \& Moustakis, 1988).

Two rounds of Delphi specialist consultations were conducted in the survey. During the implementation process, we invited nine experts and followed these steps: "select a group of experts", "provide background material", "fill in the first weight evaluation questionnaire", "give feedback to the results of the first round", "fill in the second weight evaluation questionnaire", and "summarize the results of the second round".

The consultation results analysis considered two main factors, namely the degree of items' importance and the dispersion of experts' opinions. Generally, the mean of items represents the degree of importance, and the coefficient of variation (CV) denotes the degree of dispersion. The higher the average or mean of an item is, the higher the degree of importance. The lower the CV is, the higher the degree of coordination among experts is. The cut-off value of the CV is 0.25 , 
Table 5. Cumulative variance of five dimensions.

\begin{tabular}{ccc}
\hline Factor & Variable & Cumulative Factor Loading (\%) \\
\hline F1 & Tangibles/A & 56.462 \\
F2 & Reliability/B & 69.105 \\
F3 & Responsiveness/C & 67.804 \\
F4 & Assurance/D & 70.011 \\
F5 & Empathy/E & 65.674 \\
\hline
\end{tabular}

which implies that if an indicator's CV is higher than 0.25 , it will not meet the standard in expert coordination degree (Wang \& Si, 2011).

During the first round of specialist consultation, the average mean of the 25 items in the first and second indicators is greater than 3, indicating that the items are of higher importance and are suitable for retention. The items' CV ranges from 0.07 to 0.39 , and $60 \%$ of the items are lower than 0.25 , indicating that the coordination of experts is considerable. However, the CV of 10 items exceeds 0.25 , and the majority is under the dimensions of responsiveness and empathy, showing that experts have diverse opinions when evaluating these two dimensions.

According to the experts' suggestions, the description of "hotel staff" in the dimension of assurance, responsiveness, and empathy should be expressed more accurately as "interactive equipment and staff". This proposal was adopted, and Table 6 and Table 7 show the results of the second round of specialist consultations.

The mean values of the first and second indicators are greater than 3 , and the $\mathrm{CV}$ of all items is less than 0.25 . Therefore, the second round's result represents the consensus of nine experts and can serve as a reference in the formal questionnaire.

\subsection{Data Collection}

With the help of the front desk staff from five smart hotels chosen from Table 2 randomly, the formal questionnaire was forwarded to 218 smart hotels' guests and filled in online. The sample size is based on the average occupancy rate (57\%, 179 guests) of the five smart hotels. After deleting the invalid data of 7 participants without the corresponding staying experience, the final total is 211 questionnaires. The questionnaire recovery rate was $96.79 \%$.

\section{Discussion}

\subsection{Descriptive Statistics}

The analysis of this study was executed using SPSS24.0 and EXCEL, including participants from multiple ages, distinct occupations, and various income stages. Of the 211 respondents in this study, young people aged between 19 to 30 years accounted for $70.6 \%$ of the total respondents. Most of these consumer groups 
Table 6. Weight of the first-level indicators.

\begin{tabular}{ccccc}
\hline Indicator & Mean & SD & CV & Weight \\
\hline Tangibles/A & 4.22 & 0.44 & 0.10 & 0.1990 \\
Reliability/B & 4.89 & 0.33 & 0.07 & 0.2304 \\
Responsiveness/C & 4.22 & 0.67 & 0.16 & 0.1990 \\
Assurance/D & 4.22 & 0.97 & 0.23 & 0.1990 \\
Empathy/E & 3.67 & 0.87 & 0.24 & 0.1728 \\
\hline
\end{tabular}

Table 7. Weight of the second-level indicators.

\begin{tabular}{|c|c|c|c|c|c|c|}
\hline Indicator & Items & Mean & SD & $\mathrm{CV}$ & Weight & Final Weight \\
\hline \multirow{4}{*}{ Tangibles/A } & $\mathrm{A} 1$ & 4.11 & 0.60 & 0.15 & 0.2357 & 0.0469 \\
\hline & A2 & 4.89 & 0.33 & 0.07 & 0.2803 & 0.0558 \\
\hline & A3 & 4.11 & 0.33 & 0.08 & 0.2357 & 0.0469 \\
\hline & A4 & 4.33 & 0.50 & 0.12 & 0.2484 & 0.0494 \\
\hline \multirow{4}{*}{ Reliability/B } & B1 & 5.00 & 0.00 & 0.00 & 0.2778 & 0.0640 \\
\hline & B2 & 4.56 & 0.53 & 0.12 & 0.2531 & 0.0583 \\
\hline & B3 & 4.33 & 0.50 & 0.12 & 0.2407 & 0.0555 \\
\hline & B4 & 4.11 & 0.60 & 0.15 & 0.2284 & 0.0526 \\
\hline \multirow{4}{*}{ Responsiveness/C } & $\mathrm{C} 1$ & 3.89 & 0.78 & 0.20 & 0.2381 & 0.0474 \\
\hline & $\mathrm{C} 2$ & 4.33 & 0.50 & 0.12 & 0.2653 & 0.0528 \\
\hline & $\mathrm{C} 3$ & 3.78 & 0.67 & 0.18 & 0.2313 & 0.0460 \\
\hline & $\mathrm{C} 4$ & 4.33 & 0.50 & 0.12 & 0.2653 & 0.0528 \\
\hline \multirow{4}{*}{ Assurance/D } & D1 & 4.56 & 0.53 & 0.12 & 0.2628 & 0.0523 \\
\hline & D2 & 4.56 & 0.73 & 0.16 & 0.2628 & 0.0523 \\
\hline & D3 & 3.56 & 0.53 & 0.15 & 0.2051 & 0.0408 \\
\hline & D4 & 4.67 & 0.71 & 0.15 & 0.2692 & 0.0536 \\
\hline \multirow{4}{*}{ Empathy/E } & E1 & 3.89 & 0.93 & 0.24 & 0.2593 & 0.0448 \\
\hline & E2 & 3.44 & 0.73 & 0.21 & 0.2296 & 0.0397 \\
\hline & E3 & 3.56 & 0.73 & 0.20 & 0.2370 & 0.0410 \\
\hline & E4 & 4.11 & 0.93 & 0.23 & 0.2741 & 0.0474 \\
\hline
\end{tabular}

have individual businesses or a stable job, and more than half of them are in the middle or high-income groups. Table 8 shows the demographic profiles of the respondents.

\subsection{SERVQUAL Score}

As the reliability and validity of the samples have been measured in the pilot study, we skipped these steps in the formal analysis and evaluated the service quality (SQ) score directly. According to the SERVQUAL model's calculation method, the SQ score is expressed as the gap between the guests' perceived service 
Table 8. Demographic data of the sample population $(\mathrm{N}=211)$.

\begin{tabular}{|c|c|c|c|}
\hline Characteristics & Options & Frequency & Percentage \\
\hline \multirow{2}{*}{ Gender } & Male & 86 & 40.8 \\
\hline & Female & 125 & 59.2 \\
\hline \multirow{5}{*}{ Age } & $19-30$ & 149 & 70.6 \\
\hline & $31-40$ & 36 & 17.1 \\
\hline & $41-50$ & 23 & 10.9 \\
\hline & 51 or above & 3 & 1.4 \\
\hline & Student & 44 & 20.9 \\
\hline \multirow{5}{*}{ Occupation } & Employee & 67 & 31.8 \\
\hline & Self-employed & 64 & 30.3 \\
\hline & Civil servant & 16 & 7.6 \\
\hline & Freelancer & 18 & 8.5 \\
\hline & Unemployed & 2 & 0.9 \\
\hline \multirow{4}{*}{ Monthly income (CNY) } & $<5000$ & 29 & 13.7 \\
\hline & $5,000-10,000$ & 66 & 31.3 \\
\hline & $10,000-20,000$ & 79 & 37.4 \\
\hline & $>20,000$ & 37 & 17.5 \\
\hline
\end{tabular}

(PS) score and the expected service (ES) score of the smart hotel. Multiply the SQ score by the weight shown in Table 6 and Table 7, and we generate the SERVQUAL score SQi' of each item. Table 9 and Table 10 show the final score SQ.

As for the service quality in smart hotels, the research results in Table 10 demonstrate that the guests' expectations of the five dimensions generally have high scores. Apart from empathy at 4.13, the ES scores of the other dimensions are all higher than 4.5. This outcome highlights that guests have high expectations for smart hotels, including existing facilities, abilities, speed, and enthusiasm to fulfill service commitments. In contrast, the expectations for personalized services are relatively low.

Judging from the guests' perception in Table 9, the PS scores of all 20 items are stable, and the fluctuation range remains between 3.76 and 4.34. Among them, four items have PS scores that are below 4, including three items in the dimension of empathy and the "intelligent devices and employees provide services actively" item in responsiveness. These results underline that guests consider the performance of smart hotels as ineffective in responding proactively and providing personalized services.

Overall, Table 10 shows that all dimensions have negative SQ scores, indicating the remaining gap between the services provided by smart hotels and guest expectations. Furthermore, the result depicts a durable consistency in the guests' expectations and perceptions of all five dimensions. Whether it is the mean of 
Table 9. Mean score of each item.

\begin{tabular}{|c|c|c|c|c|c|}
\hline Dimension & Items & $\mathrm{PSi}$ & $\mathrm{ESi}$ & SQi & SQi' \\
\hline \multirow{4}{*}{ Tangibles/A } & 1 & 4.33 & 4.66 & -0.33 & -0.0778 \\
\hline & 2 & 4.34 & 4.72 & -0.38 & -0.1065 \\
\hline & 3 & 4.28 & 4.59 & -0.31 & -0.0731 \\
\hline & 4 & 4.27 & 4.58 & -0.31 & -0.0770 \\
\hline \multirow{4}{*}{ Reliability/B } & 5 & 4.21 & 4.64 & -0.43 & -0.1195 \\
\hline & 6 & 4.21 & 4.61 & -0.40 & -0.1012 \\
\hline & 7 & 4.23 & 4.66 & -0.43 & -0.1035 \\
\hline & 8 & 4.26 & 4.60 & -0.34 & -0.0777 \\
\hline \multirow{4}{*}{ Responsiveness/C } & 9 & 3.99 & 4.35 & -0.36 & -0.0857 \\
\hline & 10 & 4.12 & 4.65 & -0.53 & -0.1406 \\
\hline & 11 & 4.22 & 4.63 & -0.41 & -0.0948 \\
\hline & 12 & 4.07 & 4.63 & -0.56 & -0.1486 \\
\hline \multirow{4}{*}{ Assurance/D } & 13 & 4.15 & 4.59 & -0.44 & -0.1156 \\
\hline & 14 & 4.08 & 4.64 & -0.56 & -0.1472 \\
\hline & 15 & 4.27 & 4.58 & -0.31 & -0.0636 \\
\hline & 16 & 4.07 & 4.63 & -0.56 & -0.1508 \\
\hline \multirow{4}{*}{ Empathy/E } & 17 & 3.85 & 4.34 & -0.49 & -0.1271 \\
\hline & 18 & 3.88 & 4.22 & -0.34 & -0.0781 \\
\hline & 19 & 3.76 & 4.25 & -0.49 & -0.1161 \\
\hline & 20 & 4.09 & 4.43 & -0.34 & -0.0932 \\
\hline
\end{tabular}

Table 10. Mean score of each dimension.

\begin{tabular}{cccc}
\hline Dimension & PS & ES & SQ \\
\hline Tangibles/A & 4.31 & 4.64 & -0.3344 \\
Reliability/B & 4.23 & 4.63 & -0.4019 \\
Responsiveness/C & 4.10 & 4.57 & -0.4697 \\
Assurance/D & 4.14 & 4.61 & -0.4771 \\
Empathy/E & 3.90 & 4.31 & -0.4144 \\
Overall & 4.14 & 4.55 & -0.4191 \\
\hline
\end{tabular}

expectations or the perceptions, the SQ scores from high to low are tangibles, reliability, assurance, responsiveness, and empathy.

The SQ scores of assurance and responsiveness have the lowest values, indicating that the managers need to pay more attention to "improving security" and providing "positive and prompt response". Although the PS scores of tangibles and reliability are high, their SQ scores remain negative, prompting the smart hotels to improve consistently. 
Empathy did not rank last in the SQ ranking even when personalized services had the lowest PS value and guests reduced their ES when booking a smart hotel equipped with an extensive collection of intelligent devices instead of several employees. This outcome reflects that guests are strongly tolerant of smart hotels that provide services without enough "empathy".

\subsection{Hypothesis Test}

The statistics of the online comments in preliminary research show that most of the guests in smart hotels have a positive attitude towards the tangibles and reliability. At the same time, they think that the responsiveness, assurance, and empathy of the service require significant improvements. As a result, this research formed six underlying assumptions.

However, as seen in the questionnaire analysis, the PS scores of the guests in all five dimensions are lower than their ES scores. Among these dimensions, the executions of responsiveness, assurance, and empathy are generally in either PS or ES, implying the $\mathrm{H}, \mathrm{Hc}, \mathrm{Hd}$, and He are supported. Though "tangibles" and "reliability" perform well in PS, there is a slight gap of 7\% to 9\% in the ES score. Therefore, $\mathrm{Ha}$ and $\mathrm{Hb}$ are not supported. Table 11 shows the hypothesis test results.

The results in Table 11 are consistent with the distribution of comments in preliminary research. Most of the positive comments revolve around tangibles and reliability, while the negative comments stem from the lack of responsiveness, assurance, and empathy.

Nevertheless, it is worth noting that since guests tend to have higher expectations for new industries, it is reasonable to find that existing services are unable to exceed such expectations. As a result, smart hotels must act accordingly, consider their systems in place, and implement reasonable strategies. The SQ scores ranking is the core element that deserves careful consideration. As the research shows, the five dimensions ranked from highest to lowest are tangibles, reliability, empathy, responsiveness, and assurance. This ranking reflects that while guests are more appreciative of the intelligent devices and security of smart hotels, they have negative comments toward initiatives and professionalism.

Table 11. Hypothesis test.

\begin{tabular}{lc}
\hline \multicolumn{1}{c}{ Hypotheses } & Results \\
\hline H: The PS of the entire smart hotel is worse than the expected service & Supported \\
Ha: The PS of tangibles in a smart hotel is better than the expected service & Not Supported \\
Hb: The PS of reliability in a smart hotel is better than the expected service & Not Supported \\
Hc: The PS of responsiveness in a smart hotel is worse than the expected service & Supported \\
Hd: The PS of assurance in a smart hotel is worse than the expected service & Supported \\
He: The PS of empathy in a smart hotel is worse than the expected service & Supported
\end{tabular}




\section{Discussion}

\subsection{Summary of Results}

Nowadays, many smart hotels invest heavily in purchasing intelligent devices and information systems. However, they fail to achieve their targeted returns on investments, levels of efficiencies, and profits, caused by two main reasons. First, smart hotels experience shortages in employees that have relevant expertise operating such equipment. Second, the check-in process becomes complicated because of the system used by employees who unintentionally incorporate traditional check-in processes into the updated system.

This paper primarily seeks to determine the factors that play significant roles in improving the overall quality of smart hotels. Through the field investigation, corpus analysis, and questionnaire, we have obtained several substantial results. Empirical evidence from the questionnaire shows that the PS scores of the five dimensions are all lower than the ES scores, and the SQ score of smart hotels' service quality is -0.4191 . More specifically, these results suggest that excessive advertising and marketing could heighten the expectations of consumers toward smart hotels. However, the contemporary smart hotel industry has not yet matured. This industry has no prior experiences to learn from and finds it significantly challenging to achieve standardization and high efficiency, leading to the gaps in PS and ES.

Moreover, the ranking of the five dimensions from high to low is tangibles, reliability, responsiveness, assurance, and empathy. This line up demonstrates that while guests have advanced requirements for intelligent devices and security, their demand for personalized services is relatively low.

Similarly, the research of $\mathrm{Wu}$ and Cheng showed that the dimensions of technological attachment have a positive effect on experiential trust. Moreover, they suggested that smart hotels should enable guests to identify with smart technology strongly (Wu \& Cheng, 2018). This research coincides with our survey results, where the dimension of tangibles generates the highest ES score. However, the SQ score of "empathy" conflicts with many previous studies in the hotel industry. Among the research papers in service quality across the traditional hotel industry, various scholars believe that personalized service is a crucial factor in improving guest satisfaction (Choi \& Chu, 2001; Akbaba, 2006; Wu \& Liang, 2009; Dominici \& Guzzo, 2010). In contrast, studies on smart hotels reveal that personalized service ranks last in the expectation ranking, depicting the particularity of smart hotels and the necessity for specialized research on smart hotel services.

Furthermore, our research also generates the ranking of SQ scores in smart hotels from highest to lowest: tangibles, reliability, empathy, responsiveness, and assurance. This result provides a clear direction for the subsequent developments of smart hotels. Overall, their service quality still has many defects, and there remains a big room for improvements. It is noteworthy that the absolute values of the SQ scores of all four dimensions are greater than 0.4, and the ES 
score of "empathy" has the lowest value with only 4.31. The results emphasize that the service status of smart hotels has not met guest expectations and that smart hotels should focus more on the real needs of guests and make wise investments.

\subsection{Implications of Smart Hotels}

Combining the conclusion of this paper with the service quality gap theory ( $\mathrm{Pa}-$ rasuraman, Zeithaml, \& Berry, 1985), the practical implications of this research can be summarized into three areas. First, for the "tangibles" and "reliability" with high expectations and mediocre performance, smart hotels should consider them as focal points for future developments, monitor them accordingly, and increase the investments in upgrading devices and systems. More specifically, these factors require smart hotels to replace old equipment, introduce new technologies promptly, collaborate with equipment suppliers about functional equipment designs that satisfy guest demands, and ultimately achieve a win-win situation.

On the one hand, smart hotels can enhance the interactivity between the check-in terminals and TVs in guest rooms and add practical functions such as scheduled laundry, wake-up, and taxi services. To provide a more technological and novel experience for guests, managers can also consider using virtual reality (VR) and augmented reality (AR) to exhibit three-dimensional images and anthropomorphic designs of dialogues and entertainment. On the other hand, operators and technicians must be familiar with the promotional contents of the hotel. Smart hotels must provide accurate and timely services that are on par with their publicized offers to improve guests' perception of "reliability" during their stay.

Second, as the dimensions of "responsiveness" and "assurance" rank in the middle of both ES and PS, operators should strategize a comprehensive plan for future improvements. Additionally, they should gradually increase the response speed, initiatives, and interactivity of intelligent devices.

Before purchasing systems or devices, a smart hotel should consider whether the amount of equipment aligns well with its room capacity and the number of its employees. Besides, it should fully utilize the data collected from the hotel's property management system (PMS), central reservation system (CRS), customer relationship management system (CRM), and official website. The management must study guest behaviors to determine their most and least used functions or services, ensuring high efficiency and returns. In turn, they forward this feedback to the designers to remove redundant processes, improve sensitivity to guest needs, and increase response speed.

Third, considering the low expectations for and general performance of the "empathy" dimension, smart hotels should establish the overall layout and clarify their target market and customer positioning. Given the guest preferences, smart hotels can utilize the differentiation strategy to distinguish themselves 
from competitors like traditional hotels and homestays.

Moreover, smart hotels can enrich accommodation scenarios with the assistance of informatization, digitization, and networking. For example, they could invite guests to indicate their service items of preference while booking and conduct accurate catering and entertainment services during the subsequent check-in process that reflects their original promotions.

Data collection and analysis of information such as the guest choices and length of stay should be executed to continuously expand the internal database and establish the foundation for more refined personalized services in the future.

Finally, it is worth noting that smart hotels can temporarily shelve their plans for personalized services when funds are insufficient. The more rational approach is to devote efforts to basic demands such as improving response speed, shortening service times, and enhancing the interactivity of simulated dialogue scenes.

\section{Limitations and Recommendations for Future Research}

Our results provide evidence for the distinctiveness of smart hotels, subverting the former perspective in the hotel industry that personalized service (i.e., empathy) is the foremost factor. However, our research on the service quality of smart hotels is in the primary stage due to the rapid technological advancements and sample size limitations. It requires multiple verifications of the actual situation and differences between smart hotels to confirm whether the conclusions of this study are replicable and applicable.

Furthermore, our results also provide theoretical support for the service strategy of smart hotels. The SERVQUAL model is the service quality measurement scale that is mostly applied in practice. However, the integration of diverse measurement methods such as customer effort score (CES) and new product standard (NPS) would generate more accurate conclusions (Dixon et al., 2013; Reichheld, 2003).

Ultimately, future research on smart hotels requires a broader sample size and more creative measurement methods. Most importantly, the findings should be generalizable in practice, such as providing product demand documents for designers, business strategies for the enterprises, and suggestions for talent training programs of colleges.

\section{Funding}

This research was funded by the Guangdong Provincial Science and Technology Plan Project. The grant number is 2018A070712022.

\section{Acknowledgements}

We thank the unconditional support of our colleagues who assisted us in our data collection and the anonymous reviewers for their valuable comments, which have greatly improved the manuscript. 


\section{Conflicts of Interest}

The authors declare no conflicts of interest regarding the publication of this paper.

\section{References}

Akbaba, A. (2006). Measuring Service Quality in the Hotel Industry: A Study in a Business Hotel in Turkey. International Journal of Hospitality Management, 25, 170-192. https://doi.org/10.1016/j.ijhm.2005.08.006

Andreea, N. N., \& Simona, B. (2017). Using the Eco Concept for Smart Hotel Promotion Case Study: Hotel Vega. Annals-Economy Series, 1, 27-35.

Armstrong, R. W., Mok, C., Go, F. M., \& Chan, A. (1997). The Importance of CrossCultural Expectations in the Measurement of Service Quality Perceptions in the Hotel Industry. International Journal of Hospitality Management, 16, 181-190. https://doi.org/10.1016/S0278-4319(97)00004-2

Babakus, E., \& Boller, G. W. (1992). An Empirical Assessment of the SERVQUAL Scale. Quality Engineering, 37, 607-610.

Beheshtinia, M. A., \& Azad, M. F. (2019). A Fuzzy QFD Approach Using SERVQUAL and Kano Models under Budget Constraint for Hotel Services. Total Quality Management \& Business Excellence, 30, 808-830. https://doi.org/10.1080/14783363.2017.1340830

Carman, J. M. (1990). Consumer Perceptions of Service Quality: An Assessment of the SERVQUAL Dimensions. Journal of Retailing, 66, 33-56.

Chathoth, P. K. (2007). The Impact of Information Technology on Hotel Operations, Service Management and Transaction Costs: A Conceptual Framework for Full-Service Hotel Firms. International Journal of Hospitality Management, 26, 395-408. https://doi.org/10.1016/j.ijhm.2006.03.004

Chen, R. X., \& Wang, W. J. (2005). Application of SERVQUAL in Hotel Service Quality in China. Journal of Beijing Second Foreign Studies University, 3, 59-62+77.

Choi, T. Y., \& Chu, R. (2001). Determinants of Hotel Guests' Satisfaction and Repeat Patronage in the Hong Kong Hotel Industry. International Journal of Hospitality Management, 20, 277-297. https://doi.org/10.1016/S0278-4319(01)00006-8

Dang, Z. C., \& Zhou, Z. L. (2002). Measurement and Improvement of Hotel Service Quality. Journal of Tourism, 2, 22-25.

Dixon, M., DeLisi, R., \& Toman, N. (2013). The Effortless Experience. New York: Penguin Group (USA).

Dominici, G., \& Guzzo, R. (2010). Customer Satisfaction in the Hotel Industry: A Case Study from Sicily. International Journal of Marketing Studies, 2, 3-12. https://doi.org/10.5539/ijms.v2n2p3

Jeong, M., \& Shin, H. H. (2019). Tourists' Experiences with Smart Tourism Technology at Smart Destinations and their Behavior Intentions. Journal of Travel Research, 1, 1-14. https://doi.org/10.1177/0047287519883034

Jeremen, D. E., Jędrasiak, M., \& Rapacz, A. (2016). The Concept of Smart Hotels as an Innovation on the Hospitality Industry Market-Case Study of Puro Hotel in Wrocław, Zeszyty Naukowe Uniwersytetu Szczecińskiego. Ekonomiczne Problemy Turystyki, 36, 65-75. https://doi.org/10.18276/ept.2016.4.36-06

Kaiser, H. F. (1960). The Application of Electronic Computers to Factor Analysis. Educational and Psychological Measurement, 20, 141-151. 
https://doi.org/10.1177/001316446002000116

Kapnas, G., Leonidis, A., Korozi, M., Ntoa, S., Margetis, G., \& Stephanidis, C. (2013). A Museum Guide Application for Deployment on User-Owned Mobile Devices. International Conference on Human-Computer Interaction, 3, 253-257. https://doi.org/10.1007/978-3-642-39476-8_52

Khorramshahgol, R., \& Moustakis, V. S. (1988). Delphic Hierarchy Process (DHP): A Methodology for Priority Setting Derived from the Delphi Method and Analytical Hierarchy Process. European Journal of Operational Research, 37, 347-354. https://doi.org/10.1016/0377-2217(88)90197-X

Kong, F. S., You, K., \& Hou, T. J. (2011). Service Quality Evaluation of Hotel Industry Based on Servqual Model-Taking Yingbinyuan Hotel in Enshi Prefecture, Hubei Province as an Example. China Collective Economy, 1, 137-139.

Nizic, M. K., Karanovic, G., \& Ivanovic, S. (2008). Importance of Intelligent Rooms for Energy Savings in the Hotel Industry. Tourism Hospitality Management, 14, 323-336.

Nunnally, J. (1978). Psychometric Theory(2nd ed.). New York: McGraw-Hill.

Parasuraman, A., Zeithaml, V. A., \& Berry, L. L. (1985). A Conceptual Model of Service Quality and Its Implications for Future Research. Journal of Marketing, 49, 41-50. https://doi.org/10.1177/002224298504900403

Parasuraman, A., Zeithaml, V. A., \& Berry, L. L. (1988). SERVQUAL: A Multiple-Item Scale for Measuring Consumer Perceptions of Service Quality. Journal of Retailing, 64, 12-40.

Reichheld, F. F. (2003). The One Number You Need to Grow. Harvard Business Review, 81, 46-54.

Saleh, F., \& Ryan, C. (1991). Analysing Service Quality in the Hospitality Industry Using the SERVQUAL Model. Service Industries Journal, 11, 324-345.

https://doi.org/10.1080/02642069100000049

Solnet, D., Baum, T., Robinson, R. N. S., \& Lockstone-Binney, L. (2016). What about the Workers? Roles and Skills for Employees in Hotels of the Future. Journal of Vacation Marketing, 22, 212-226. https://doi.org/10.1177/1356766715617403

Stefano, N. M., Filho, N. C., Barichello, R., \& Sohn, A. P. (2015). A Fuzzy SERVQUAL Based Method for Evaluated of Service Quality in the Hotel Industry. Procedia CIRP, 30, 433-438. https://doi.org/10.1016/j.procir.2015.02.140

Stepan, J., Cimler, R., \& Krejcar, O. (2018). Automation System Architecture for a Smart Hotel. International Conference on Computational Collective Intelligence, 7, 457-466. https://doi.org/10.1007/978-3-319-98446-9_43

Tribe, J., \& Snaith, T. (1998). From SERVQUAL to HOLSAT: Holiday Satisfaction in Varadero, Cuba. Tourism Management, 19, 25-34. https://doi.org/10.1016/S0261-5177(97)00094-0

Tuominen, P. P., \& Ascenção, M. P. (2016). The Hotel of Tomorrow: A Service Design Approach. Journal of Vacation Marketing, 22, 279-292. https://doi.org/10.1177/1356766716637102

Venkatesh, V., Vaithayana, V., Raj, P., Gopalan, K., \& Amirtharaj, R. (2013). Envisioning Smart Hotels through Spontaneous Device Integration. Research Journal of Information Technology, 5, 226-233. https://doi.org/10.3923/rjit.2013.226.233

Wang, C. Z., \& Si, Q. (2011). Research on Data Statistics Processing Method and Its Application in Delphi Method. Journal of Inner Mongolia University of Finance and Economics, 9, 92-96.

Wang, J., Bao, Z., \& Yang, Y. (2017). Design of Power Monitoring System on Smart Ho- 
tel. International Symposium on Computational Intelligence and Design (ISCID), Hangzhou, 9-10 December 2017, 312-315. https://doi.org/10.1109/ISCID.2017.232

Wu, B. (2019a). Analysis of the Status and Future Development of Smart Hotels. Chinese Travel News, 31 January, A02.

Wu, H. Y. (2019b). Development Motivation, Current Situation, Problems and Countermeasures of Smart Hotel Industry in China. Operation and Management, 4, 95-99.

Wu, C. H.-J., \& Liang, R.-D. (2009). Effect of Experiential Value on Customer Satisfaction with Service Encounters in Luxury-Hotel Restaurants. International Journal of Hospitality Management, 28, 586-593. https://doi.org/10.1016/j.ijhm.2009.03.008

Wu, H.-C., \& Cheng, C.-C. (2018). Relationships between Technology Attachment, Experiential Relationship Quality, Experiential Risk and Experiential Sharing Intentions in a Smart Hotel. Journal of Hospitality and Tourism Management, 37, 42-58. https://doi.org/10.1016/j.jhtm.2018.09.003

Wu, L. (2019c). Assumption of Overseas Construction and Expansion of 5G Smart Hotel. Jiangke Science Research, 14, 47-50.

Xiong, W., \& Wu, Y. M. (2018). Research on the Influence of Wisdom on the Performance of High-Star Hotels in the Pearl River Delta Region. Journal of Tourism, 33, 75-86.

Yao, G. Z., \& Han, L. H. (2013). Application of Internet of Things in Smart Tourism. China Business Review, 8, 117-118.

Zeng, H., \& Lu, S. (2017). Research on the Status and Future of Smart Hotels under the Background of Big Data-Taking Changsha Star-Rated Hotels as an Example. Technology and Market, 24, 132-134.

Zhong, Y., \& Gao, J. F. (2017). Discussion on Problems and Countermeasures of Chinese Smart Hotel Construction. Commercial Economic Research, 18, 174-178. 


\section{Appendix A. Formal Questionnaire}

Table A1. Items of the questionnaire.

\begin{tabular}{|c|c|c|}
\hline Dimension & Number & Items \\
\hline \multirow{4}{*}{ Tangibles/A } & A1 & Modern and comfortable looking \\
\hline & $\mathrm{A} 2$ & Complete and intelligent equipment \\
\hline & $\mathrm{A} 3$ & The consistent and recognizable style \\
\hline & A4 & All necessary items can be provided during the stay \\
\hline \multirow{4}{*}{ Reliability/B } & B1 & The services are reliable and professional \\
\hline & B2 & The services can be completed eventually \\
\hline & B3 & The services can be completed timely as promised \\
\hline & B4 & Spare no effort to help solve the guests' problem \\
\hline \multirow{4}{*}{ Responsiveness/C } & $\mathrm{C} 1$ & Interactive equipment and staff provide services actively \\
\hline & $\mathrm{C} 2$ & Interactive equipment and staff response promptly \\
\hline & $\mathrm{C} 3$ & Interactive equipment and staff response willingly \\
\hline & $\mathrm{C} 4$ & $\begin{array}{l}\text { Interactive equipment and staff provide the accurate time that } \\
\text { performing service }\end{array}$ \\
\hline \multirow{4}{*}{ Assurance/D } & D1 & Interactive equipment and staff instill confidence in guests \\
\hline & D2 & Interactive equipment and staff make guests feel safe \\
\hline & D3 & Interactive equipment and staff are consistently courteous \\
\hline & $\mathrm{D} 4$ & Interactive equipment and staff can satisfy customers \\
\hline \multirow{4}{*}{ Empathy/E } & E1 & Interactive equipment and staff give guests individual attentions \\
\hline & $\mathrm{E} 2$ & $\begin{array}{l}\text { Interactive equipment and staff proactively follow guests and } \\
\text { provide services }\end{array}$ \\
\hline & E3 & Interactive equipment and staff provide services in a caring fashion \\
\hline & $\mathrm{E} 4$ & Convenient business hours \\
\hline
\end{tabular}

\section{Appendix B. Pictures of Field Survey}

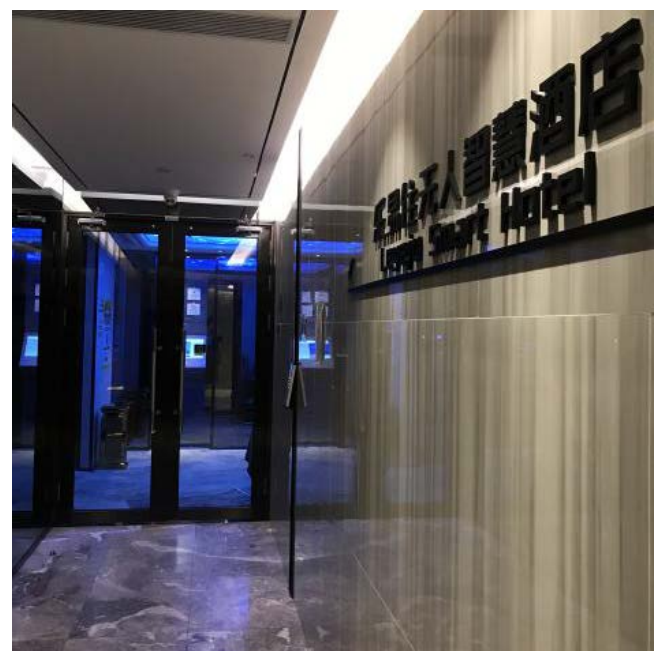

Figure B1. Access control system of smart hotel's lobby. 


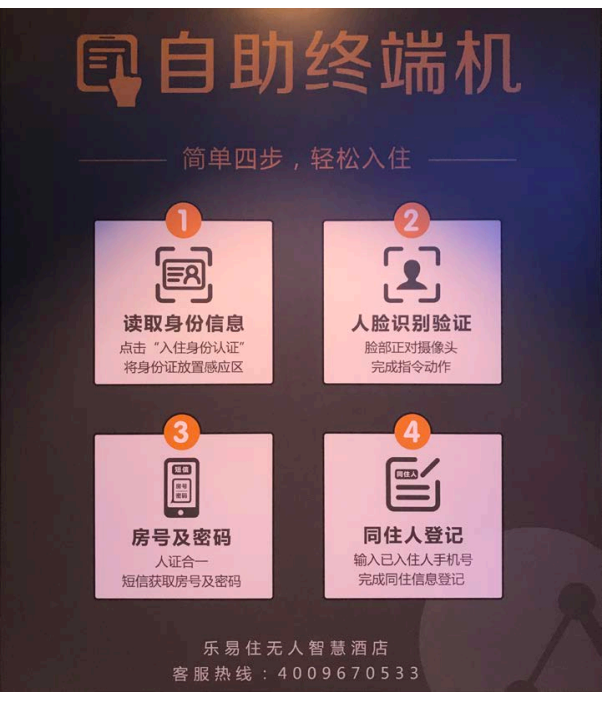

Figure B2. Check-in terminal of smart hotel.

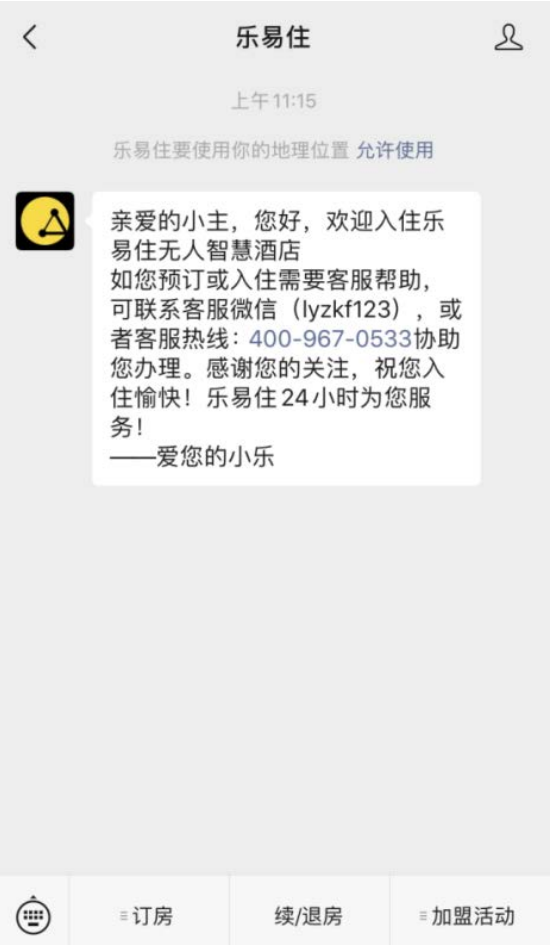

Figure B3. Official account of smart hotel. 